\title{
Resenha
}

LAGROU, Els e SEVERI, Carlo (orgs.). Quimeras em diálogo - grafismo e figuração na arte indígena. Rio de Janeiro, Editora 7 Letras, 2013, 366 pp.

\section{Percorrendo atos do olhar: novas perspectivas sobre a arte indígena}

\author{
Luiza Serber \\ Universidade de Campinas, Campinas, SP, Brasil \\ luizaserber@yahoo.com.br
}

Gabriela Aguillar

Universidade de Campinas, Campinas, SP, Brasil

gabrielaaguillarleite@gmail.com

Propondo uma antropologia da percepção e preocupado com os atos do olhar, o livro Quimeras em diálogo - grafismo e figuração na arte indígena, organizado por Carlo Severi e Els Lagrou, explora a relação entre regimes de conhecimento particulares - sobretudo ameríndios - e a produção de imagens. Esta relação é concebida de forma inovadora através do conceito de quimera, introduzido por Severi em obras anteriores e ganhando notoriedade em Le Principe de la chimère (2007). Tal como explicado na introdução do livro, esta coletânea remonta sua origem a um simpósio realizado no Rio de Janeiro em 2011 que reuniu muitos dos autores presentes na obra. Nela, encontram-se artigos voltados à investigação de dois tipos de relação entre formas visuais: "a relação entre grafismo e a figuração (e/ou desfiguração) dos corpos, por um lado, e a relação entre cognição e percepção, por outro" (: 12). Guiados por estes eixos, reconhecemos uma busca por articular determinados universos ontológicos com suas respectivas convenções estéticas tornadas visíveis através de produções gráficas. Esta busca reflete ideias já presentes em estudos anteriores de Lagrou e de Severi. Segundo a própria autora, há algum tempo seu "tema de reflexão tem sido relacionar um estilo de ver e de mostrar com um estilo de pensar" (: 68). Severi, ao apresentar as imagens quiméricas como produtoras de certas relações lógicas (entre representação icônica e indicação indiciária), também já apontava para esta relação. 
Esta coletânea propõe e realiza um importante deslocamento teórico que permite que processos criativos envolvidos na produção de imagens possam ser pensados para além da chave dicotômica que opõe procedimentos de convenção aos de invenção. Em seu lugar, estes procedimentos são entendidos como expressões interdependentes de uma simbolização por meio da qual contextos novos são agenciados a partir de universos referenciais familiares. Ademais, o livro realiza a significativa passagem analítica "de uma ênfase na arte enquanto sistema de comunicação para uma abordagem praxiológica onde se dá destaque à centralidade da agência da imagem" (: 11). Evidencia-se assim o diálogo que a presente obra estabelece com o livro Grafismo indígena, editado por Lux Vidal (1992) aproximadamente trinta anos antes.

Este destaque atribuído ao caráter agentivo das produções imagéticas é central na obra. De acordo com esta abordagem, os grafismos e as figurações atuariam como índices materiais nas redes de interações sociais em que são concebidos e sobre as quais produzem efeitos. Essa concepção de agência é trazida por muitos autores através das elaborações de Alfred Gell (1998) que apontam para um novo modo de se pensar arte na antropologia. A partir das operações mentais que obras e objetos artísticos suscitam à cognição, estes podem ser pensadas enquanto nexos entre relações. $\mathrm{Na}$ medida em que possuem a qualidade de apontar/indicar as redes de intencionalidades conformadas em suas materialidades, atuam como pontos mediadores entre interações sociais.

É também fundamental na abordagem apresentada a consideração da qualidade perspectiva do pensamento ameríndio, desenvolvida na obra de Eduardo Viveiros de Castro. Segundo ele, neste sistema ontológico, a distinção clássica entre as categorias natureza e cultura não opera da forma como convencionalmente a compreendemos. Em contextos ameríndios, natureza e cultura não assinalam regiões do ser, mas antes pontos de vista (1996: 116). A resistência do pensamento ameríndio a se "enquadrar" aos termos de nossos debates epistemológicos sugere a necessidade de suspeitarmos dos referentes conceituais mobilizados para se analisar a produção artística. O reconhecimento nesta coletânea do caráter perspectivista do pensamento ameríndio indica que tal suspeita foi levantada pelos autores, resultando em um reembaralhamento conceitual que incide sobre a análise das produções visuais. Reconhece-se que todo ponto de vista envolve determinadas formas de percepção e produção visual.

Abrindo a sequência de textos da coletânea, "O espaço quimérico. Percepção e projeção nos atos do olhar" de Carlo Severi, propõe-se a abordar as operações mentais implicadas nesses 
atos. Ele considera que as relações entre percepção e projeção são definidoras da construção cultural de uma imagem, que se particulariza dentro de uma tradição gráfica e figurativa. Após se ater, em um primeiro momento, a convenções familiares ao nosso universo visual ocidental, Severi volta-se ao caso específico das representações quiméricas. Ele analisa - segundo parâmetros estéticos, morfológicos e lógicos - de que maneira esse tipo de representação opera a partir de seus efeitos visuais. A quimera grega e suas configurações em imagens duplas é contraposta à quimera que se funda a partir de referentes múltiplos. Uma representação deste segundo tipo, presente de modo exemplar na arte ameríndia, nos deixa à mostra fragmentos visuais que nos indicam um jogo de relações complexas e instáveis entre as partes visíveis e invisíveis da imagem. Apenas implícitas, essas partes invisíveis requerem um ato de projeção do olhar para que sejam apreendidas. A representação é aqui tratada como uma "rememoração" de uma imagem percebida e organizada a partir de uma experiência subjetiva, sempre apreendida a partir de um quadro referencial particular. Compreende-se, então, a observação da realidade como sendo mediada por um certo enquadramento do olhar, no lugar de se pensar a representação como uma apreensão não mediada do real.

No artigo "Podem os grafismos ameríndios ser considerados quimeras abstratas? Uma reflexão sobre uma arte perspectivista", Els Lagrou propõe que as imagens e os grafismos ameríndios sejam compreendidos como instrumentos perceptivos atuantes em uma ontologia caracterizada pela transformabilidade das formas e dos corpos. A autora parte

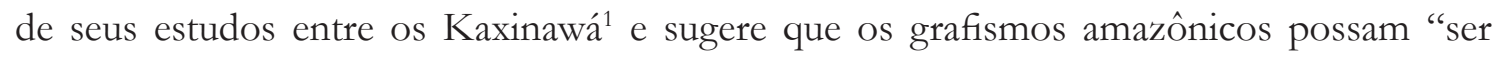
interpretados como técnicas perspectivistas [...] que permitem ao expectador mudar de ponto de vista graças a um enquadramento (framing) específico" (: 68). Lagrou tece ao longo do texto uma relação entre o perspectivismo ameríndio e o conceito de quimera resultando na noção de quimera abstrata. Segundo a autora, as produções visuais destas sociedades se caracterizam pela tendência de sugerir, mais que mostrar ou representar. Trata-se de um universo estético constituído pela tensão existente entre o visível e o invisível, e é através do desenho que se opera a passagem entre essas duas esferas. O olhar engaja-se ativamente no preenchimento de lacunas sugeridas pelos grafismos que se deixam ver, grafismos estes marcados pela "economia no uso da representação figurativa" (: 78). Ainda que abstrata, esta forma de arte possibilita a apreensão de imagens mentais que, apesar de ausentes nos desenhos, podem ser vislumbradas por aqueles preparados para visualizá-las. Esta visualização está condicionada a uma série de técnicas perceptivas mobilizadas particularmente em contextos rituais. O uso ritual dos grafismos evidencia seu caráter agentivo uma vez que eles próprios engendram 
uma transformação da percepção e atuam sobre a pele dos corpos que recobrem. Uma vez aplicados nos corpos, os desenhos desempenham um papel fundamental em sua fabricação.

Em seguida, "Perspectiva xamânica: relações entre rito, narrativa e arte gráfica", de Esther Jean Langdon, trata dos Siona² que realizam rituais de ingestão de yagé (ayahuasca) para suas experiências com o mundo dos espíritos. Partindo da compreensão desta arte como constituinte de um universo intertextual mais amplo, articulam-se cantos, narrativas e ritos com desenhos gráficos. A autora nos convida a olhar para uma relação conjunta entre a concepção dos desenhos e a prática xamânica, em que a experiência da memória subjetiva dos xamãs é responsável por tornar visíveis, a partir das figuras geométricas, relações com o mundo oculto. Conhecer o desenho envolve, segundo Langdon, a capacidade do xamã de contatar esta outra esfera e necessita, para tanto, desenvolver três capacidades interdependentes em suas performances: "cantar", "ver" e "pensar". Frutos de seleção e combinação, motivos gráficos semelhantes sempre apresentam diferenças no modo como têm seus elementos organizados, o que indica particularidades na própria relação estabelecida entre o xamã e os seres invisíveis do cosmos.

O artigo seguinte, "Homens, Guaribas, Mandiocas e artefatos" de Lúcia Hussak van Velthem, trata da cosmologia Wajana ${ }^{3}$. A autora apresenta o papel fundamental desempenhado pelas técnicas de transformação corporal a fim de conferir aos corpos o estatuto de humanidade ou de pessoa. Segundo van Velthem, a necessidade de aplicar sobre os corpos pinturas e grafismos decorre de sua necessária distinção dos demais componentes cosmológicos, como animais, artefatos e espíritos. Estas marcas cromáticas e iconográficas se configuram como um elemento diferenciador que permite que os Wajana afirmem sua humanidade. Neste contexto, tanto pessoas quanto coisas são tidas como corpos fabricados e, portanto, encontram-se estreitamente associados. A pele figura como um importante suporte de traços decorativos e também como elemento mediador entre diferentes domínios. Para a autora, nesta cosmologia, as cores constituem-se como um mecanismo classificatório, proporcionando "a mais fundamental das ordenações" (: 146) que encontra seu substrato nas narrativas míticas. Por conseguinte, a pintura revela-se entre os Wajana como a mais importante das técnicas transformativas.

Em “Arte gráfica Asuriní do Xingu: Corpo, mito e pensamento”, Regina Polo Müller nos oferece uma visão da arte deste povo ${ }^{4}$ e busca articular as relações existentes entre a figuração dos corpos, a mitologia, as categorias do pensamento e a performance ritual. Em particular, atenta-se para a correspondência entre o desempenho performático no ritual e a produção do corpo figurado através do uso de adornos específicos. A autora analisa a 
pintura de desenhos geométricos sobre os corpos, que, segundo ela, enfatizam e realizam a condição humana. Outra situação, em contraste, constitui-se pela figuração do corpo quando inteiramente coberto por uma pintura preta, o que possibilita a incorporação de seres míticos que evidenciam uma situação de liminaridade perigosa. Mediante tais observações, a autora salienta o imbricamento existente entre o exercício expressivo da imagem e a constituição do ser, relação expressa particularmente pelo padrão tayngava. Têm-se então uma análise que propõe pensar conjuntamente pintura, superfície e ontologia.

Em seu artigo "O trançado, a música e as serpentes da transformação no Alto Xingu”, Barcelos Neto enfoca sua análise no caráter intersemiótico da cultura material e dos rituais Wauja ${ }^{5}$. Ele mostra como, neste universo, personagens míticos encontram-se diretamente relacionados aos trançados de palha e às expressões sonoras. Com referência aos estudos de Menezes Bastos, Barcelos Neto desenvolve a teoria da cadeia intersemiótica do ritual, segundo a qual o ritual seria o campo de realização de uma cadeia de transformações semióticas que conectam formas verbais, visuais e sonoras. Neste mundo transformacional, composto por múltiplas perspectivas, constata-se que uma rígida divisão entre visual e sonoro se mostra inconsistente. Segundo ele, "não se trata, portanto, de uma ideia de representação do sonoro pelo visual, mas de que o visual se torna, de fato, sonoro de acordo com o ponto de vista em questão" (: 184). Esta constituição conjunta de elementos sonoros e visuais encontra-se expressa também no domínio mitológico. O autor conclui que as três serpentes - Arakuni, Kamalu Hai e Pulupulu - tidas como metáforas transformacionais, são representantes de um grande tema das artes ameríndias. Segundo ele, nenhum outro personagem, nem mesmo a onça, recebeu traduções visuais tão impressionantes, o que "demonstra o extraordinário rendimento artístico das serpentes e a trama complexa que elas tecem entre sensibilidades estéticas e noções cosmológicas" (: 195).

Seguimos com o artigo de Luisa Elvira Belaunde, "Movimento e profundidade no kene shipibo-konibo da Amazônia Peruana”. Na discussão acerca deste povo ${ }^{6}$, Belaunde aborda os movimentos de percepção e leitura das imagens. Estes movimentos são engendrados pela forma como os desenhos são construídos, resultando em um efeito visual particular. Nas palavras de Belaunde, a composição dos desenhos "constituem técnicas de focalização do olhar cujo efeito sinestésico consiste em sugar o espectador para dentro do espaço gráfico" (: 199). A relação que o desenho estabelece com a superfície - a figura com o fundo - cria um jogo de movimento e profundidade que possibilita o trânsito entre camadas (ou entre pontos de vista) permitindo a passagem entre mundos perceptivos. A autora propõe que "antes de 
pretender decifrar o suposto significado dos desenhos é necessário aprender a vê-los” (: 202). A agentividade dos grafismos é também aqui enfatizada, atuando diretamente sobre a pele que recobrem, ora aumentando sua permeabilidade para uma intervenção externa, ora fechando-os e protegendo-os desta exterioridade.

No artigo "Kempiro. A Arte gráfica dos traços fortes entre os Ashaninka do Oeste Amazônico", Peter Beysen enfatiza o caráter minimalista desta arte e a relação existente entre beleza e perigo. Dado que os Ashaninka ${ }^{7}$ estão imersos em um mundo altamente transformacional, a fabricação de corpos através de pinturas que exprimem pontos de vista envolve uma série de riscos potenciais. Aquele que não executa bem o desenho da cobra kekempiro, por exemplo, corre o risco de sofrer uma vingança da serpente. Trata-se então de uma "estética de poder, uma admiração que é provocada, às vezes, pela beleza mais letal possível" (: 224), ideia que dialoga com a obra O Belo é a Fera de Van Velthem (2003) sobre a arte Wajana. O motivo ashaninka da teia de aranha evidencia o jogo cognitivo que se dá entre percepção e projeção no espaço visual, uma vez que o olhar é guiado para completar mentalmente as linhas invisíveis da teia.

André Demarchi, em "Figurar e desfigurar o corpo: peles, tintas e grafismos entre os Mebengôkrê (Kayapó)", privilegia o caráter performático da pintura corporal e destaca sua agência na produção da pessoa. Entre os Mebêngôkre" ${ }^{8}$, a pintura corporal figura como um importante marcador social associado às diferentes etapas de produção do corpo realizadas ao longo da vida. A capacidade agentiva dos motivos gráficos é o que define seu uso em cada uma dessas etapas. Uma das formas de pintura tratada por Demarchi é uma espécie de "dripping selvagem", cujo nome (kran a menh 'ôk ) se refere à performance envolvida em sua feitura. Esta pintura é realizada por homens e está ligada ao ritual de afirmação do caráter duro de seus corpos, o que os faz aptos a suportarem tamanha desorganização gráfica. Segundo Demarchi, este "antimotivo" difere radicalmente das outras formas de pintura corporal mebêngôkre que são marcados por sua simetria e homogeneidade. A pintura mostra-se elemento essencial na constituição da pele, entendida como fronteira que envolve e dá forma aos corpos. Os grafismos, portanto, também atuam enquanto proteção, uma vez que são necessários à fabricação da pele, sem a qual o corpo seria demasiadamente fluído e sujeito à agência de seres externos.

Em “Tambor e espaço virtual no xamanismo cacasse”, Charles Stepanoff aborda a organização espacial das iconografias nos tambores de xamãs da Ásia setentrional. O autor dialoga com a questão da intertextualidade das linguagens dentro do campo da ação ritual. Sua preocupação está centrada nas relações para as quais apontam essas imagens através 
de sua articulação com os cantos e o corpo do xamã. Revela-se, assim, uma aproximação entre a estruturação sequencial dos cantos e a organização espacial dos desenhos no tambor, que ajudam na memorização e garantem um bom desempenho ritual. Novamente nos é apresentada uma leitura praxiológica dos desenhos, na qual a atenção está voltada para a dimensão sinestésica da relação entre corpo e espaço. As imagens, antes de serem importantes por transmitirem mensagens para os xamãs, são as responsáveis por auxiliá-los, guiando seus olhares nas viagens realizadas durante os rituais: “O tambor supostamente servia de montaria para o xamã durante suas viagens através do universo e acontecia de ser cavalgado por ele" (: 279). Esta relação entre imagem e "guia" em contexto siberiano aparece de forma análoga ao que pode ser observado em contextos amazônicos.

Encerrando, "A máscara do animista: quimeras e bonecas russas na América indígena" de Carlos Fausto amarra a proposta de se compreender as potencialidades da noção de quimera ao olhar para as diferentes formas de arte indígena. O autor realiza esta reflexão através do desdobramento das relações entre humanos, animais e espíritos nas máscaras de povos indígenas americanos. Resgata-se no artigo um movimento, seguido por Severi e percorrido inversamente por Lagrou, de conciliação entre uma possível universalidade da resposta humana às imagens e a particularidade de ontologias e suas representações. Para pensar essa relação, o autor enuncia duas propriedades formais típicas das máscaras analisadas: o "encaixe recursivo" e a "referência múltipla”. Ele propõe que as máscaras podem ser mais bem pensadas em sua eficácia enquanto objetos rituais, devendo ser vestidas para produzir efeitos. A presença que a máscara sugere é mais profícua - e dialoga mais diretamente com a instabilidade cognitiva de seus arranjos formais - que a definição das identidades a que elas se referem. Isso porque essas identidades são turvas, múltiplas e marcadas pela capacidade transformativa própria de seus universos cognitivos.

Dentre o conjunto teórico que entrelaça arte e antropologia, esta obra destaca-se por reunir não apenas importantes autores, mas ideias e teorias fecundas neste encontro. A combinação de preocupações estéticas e cognitivas - elaborada no livro de maneira inovadora - constitui-se como eixo fundamental para reflexões acerca dos universos imagéticos que perpassam as mais diversas realidades ontológicas. As reflexões são ainda extremamente enriquecidas por uma edição repleta de fotografias, pinturas e desenhos que não desempenham um papel meramente ilustrativo, mas dão sentido aos atos do olhar. 


\section{Notas}

${ }^{1}$ Habitantes da Amazônia brasileira ocidental e pertencentes à família pano (ISA. Povos Indígenas no Brasil. Disponível em: <https://pib.socioambiental.org/pt>. Acesso em 10 de setembro de 2016).

${ }^{2}$ Habitantes da fronteira da Amazônia colombiana com o Equador e pertencentes à família tukano (Ibidem).

${ }^{3}$ Habitantes do norte do Estado do Pará e pertencentes à família karib (Ibidem).

${ }^{4}$ Habitante do estado do Pará e pertencente à família tupi-guarani (Ibidem).

${ }^{5}$ Habitantes do Mato Grosso e pertencentes à família aruak (Ibidem).

${ }^{6}$ Pertencente à família pano (Ibidem).

${ }^{7}$ Pertencentes à família aruak (Ibidem).

${ }^{8}$ Habitantes dos estados do Mato Grosso e Pará e pertencentes à família jê (Ibidem).

\section{Referências bibliográficas}

GELL, Alfred

1998 Art and Agency: An Anthropological Theory. Oxford, Oxford University Press.

Severi, Carlo

2007 Le Principe de la chimère, une anthropologie de la mémoire. Paris, Ed. Rue d’Ulm-musée du quai Branly.

Severi, Carlo e Lagrou, Els (orgs.)

2013 Quimeras em diálogo - grafismo e figuração na arte indígena. Rio de Janeiro, 7 Letras.

VeLthem, Lucia Hussak van

2003 O Belo é a Fera. A estética da produção e da predação entre os Wayana. Lisboa, Museu Nacional de Etnologia.

VIDAL, Lux (org.)

1992 Grafismo indígena. São Paulo, Studio Nobel, Fapesp/Edusp.

Viveiros de Castro, Eduardo

1996 “Os Pronomes Cosmológicos e o perspectivismo ameríndio”. Mana, 2 (2):

$115-144$. 